\title{
Study of the mortality mechanisms of yeasts in fermentation: Role of micronutrients limitations and nitrogen
}

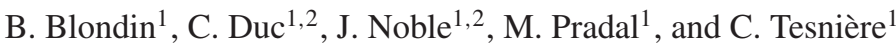 \\ ${ }^{1}$ UMR SPO, INRA, Montpellier SupAgro, Université de Montpellier, Montpellier, France \\ ${ }^{2}$ Lallemand SAS, Blagnac, France
}

\begin{abstract}
Yeast cell death can occur during wine alcoholic fermentation and lead to sluggish or stuck fermentations. The mechanisms underlying cell death during yeast starvation in alcoholic fermentations remain unclear. In this work we addressed yeast cell death using conceptual framework from ageing studies showing that yeast resistance to starvation can be influenced by the nature of the nutrient limiting cell growth. We examined cell death occurrence considering yeast cells ability to elicit an appropriate response to a set of nutrient limitations. We show that several micronutrients limitations (oleic acid, ergosterol, pantothenic acid and nicotinic acid) trigger cell death in a nitrogen-dependent manner. We provide evidence that the nitrogen Tor/Sch9 signaling pathway is involved in triggering cell death. In such conditions, yeast cells fail to acquire stress resistance given a restriction at a post-transcriptional level. We have examined the ability of different nitrogen sources to trigger cell death and show that they impact differentially on cell death and that $\mathrm{NH}_{4}^{+}$had a strong death inducing capacity. Finally, the QTLs approaches allowed the mapping of a set of loci controlling cell death under oleic acid and pantothenic acid starvation consistent with a multigenic control.
\end{abstract}

\section{Introduction}

During wine alcoholic fermentation, yeast cells can lose their viability, which leads to sluggish or stuck fermentations [1]. Loss of viability during alcoholic fermentation is usually attributed to an insufficient availability of lipids, specifically sterols or unsaturated fatty acids, given that a membrane deficiency in these compounds is thought to alter cell resistance to ethanol [2]. Actually the mechanisms leading to cell death in wine alcoholic conditions are unclear. Recent studies on cell death have shown that yeast can die more or less rapidly depending on the conditions that trigger growth stop. An important conclusion from ageing studies is that yeast resistance to starvation can be influenced by the nature of the nutrient limiting cell growth [3]. In this work we addressed yeast cell death using conceptual framework from ageing studies showing that yeast resistance to starvation can be influenced by the nature of the nutrient limiting cell growth. We show here that several micronutrients limitations (lipids and vitamins) lead to cell death and stuck fermentations in a nitrogen-dependent manner. We also show that yeast cell death under micronutrient limitation is controlled by the availability of residual nitrogen. Moreover, we observed that cell death is dependent on the nature of nitrogen sources and that some nitrogenous compounds, including ammonium salts, had a high capacity to trigger cell death while other had reduced impact.

\section{Materials and methods}

\subsection{Strains}

We used the commercial wine yeast strain Lalvin EC1118®, a Saccharomyces cerevisiae strain.

\subsection{Fermentation conditions}

Alcoholic fermentations were carried on in a synthetic medium that mimics a natural grape must with $230 \mathrm{~g} / \mathrm{L}$ mix glucose and fructose. The amount of assimilable nitrogen was provided by amino acids and/or $\mathrm{NH}_{4}^{+}$depending fermention experiments.

\subsection{Cell viability determination}

Cells viability was determined by flow cytometry using a C6 cytometer and propidium iodine labeling and analysis usin and Accuri cytometer.

\section{Results and discussion}

\subsection{Micronutrient limitations can trigger cell death when associated to high nitrogen levels}

In order to assess whether micronutrient limitations could trigger yeast cell death during alcoholic fermentation, strain EC1118® was set to ferment in a synthetic fermentation medium SM425 (containing $425 \mathrm{mg} / \mathrm{L}$ of yeast assimilable nitrogen) with various micronutrient limitations. We examined the response to limitations in ergosterol and oleic acid (given the yeast cell requirements for these two compounds in anaerobiosis), thiamin, biotin, inositol, pantothenic acid and nicotinic acid. The impact of these micronutrient limitations was examined using two levels of assimilable nitrogen. For each micronutrient limitation we used a low level of Nass that permit an indentical biomass formation compared to the limiting micronutrient. As shown Fig. 1, when the ergosterol is limiting in situation of high nitrogen level an important cell death is observed. However, when the amount of

(C) The Authors, published by EDP Sciences. This is an Open Access article distributed under the terms of the Creative Commons Attribution License 4.0 (http://creativecommons.org/licenses/by/4.0/). 


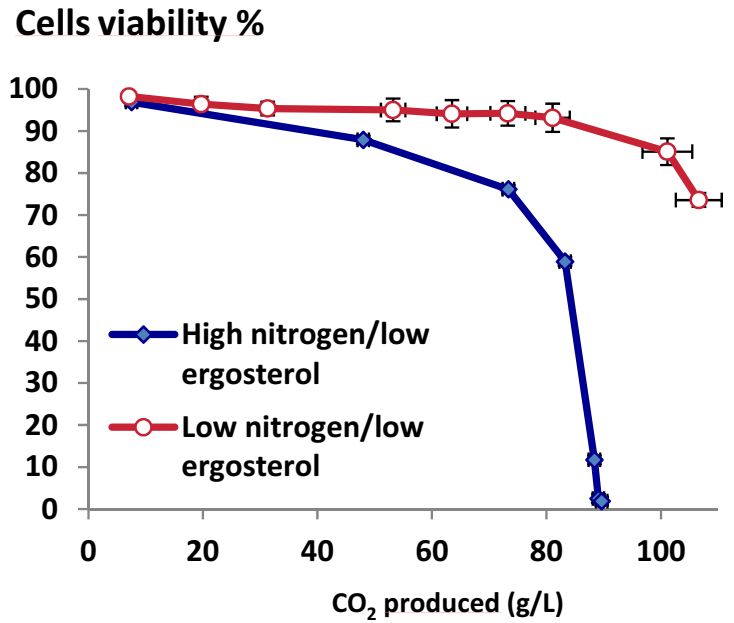

Figure 1. Impact of nitrogen amount on the cell viability of an ergosterol-limited fermentation. Ergosterol was $1.5 \mathrm{mg} / \mathrm{L}$ in each situation. Open circle: $71 \mathrm{mg} / \mathrm{L}$ of Nass; filled circle: $425 \mathrm{mg} / \mathrm{L}$ Nass.

assimilable nitrogen was adjusted to a minimal to support growth to an identical amount, the viability of the yeast cells was restored. Cell death under ergosterol limitation is dependent on the level of nitrogen in the medium.

Cells viability evolution was examined in fermentations limited other micronutrients. We observed a similar nitrogen dependent yeast cell death in fermentation that were limited with oleic acid, pantothenic acid and nicotinic acid (data not shown). In each case lowering the nitrogen level restored yeast viability indicating that all these cell death obey to a similar mechanism $[4,5]$. Thus, the amount of assimilable nitrogen modulates the yeast cell death associated with micronutrient limitations. These results indicate that the residual nitrogen sources are involved in triggering cell death when high nitrogen levels are used. Indeed we could observed in all these situation there was a residual nitrogen in the fermentation media.

\subsection{High nitrogen levels can lead to stuck fermentations in micronutrient-limited medium}

Cells viability has an impact on the fermentation capacity of the that can be observed on the fermentation kinetics. As shown Fig. 2, an ergosterol-limited fermentation was slow when the level of nitrogen was low but sugars were fermented to completion. However, when the level of Nass was high, the beginning of the fermentation was quicker but it led to a stuck fermentation with $40 \mathrm{~g} / \mathrm{L}$ of residual sugars. Therefore, in this situation a high nitrogen level favoured stuck fermentation. A similar response was observed for each micronutrient limitation leading to cell death.

High levels of assimilable nitrogen have clearly a detrimental impact on cell death when associated to limiting amount of a set of micronutrients. However, all micronutrient do not have the capacity to trigger cell death in these situation. Biotine, thiamine, inositol limitation did not display such a nitrogen-dependent cell death (data not shown, plos one).

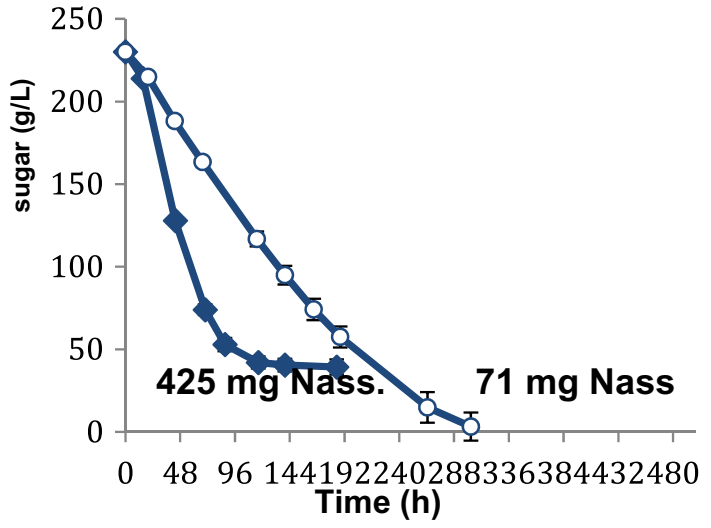

Figure 2. Impact of nitrogen level on the fermentation kinetic of an ergosterol-limited fermentation. Sugar profile with 71 and $425 \mathrm{mg} / \mathrm{L}$ Nass.

\subsection{Micronutrient limitations do not trigger a stress response}

To specify the mechanisms involved in cell death we examined the impact on the nutrient limitations on the set up of a stress resistance by yeast cells. We measured the acquisition of a stress resistance by yeast by checking its ability to resist to a heat chock. We observed that while in nitrogen limited fermentations yeast cell acquired a strong heat chock resistance upon entry into starvation, this resistance was not developed when micronutrients were limiting the growth (data not shown, plos one). The lack of acquisition of a stress resistance overlapped perfectly with the ability of yeast to stay alive in the fermentation indicating that it was a critical event for fermentation outcome. The set up of stress resistance involves several steps that include both a transcrptional response (corresponding to stress genes enhanced expression) and to post-transriptional events. Tranciptomic analyses revealed that stress response was correctly set up by all nutrient limitations including micronutrients. This indicates that the lack of a stress resistance of yeast in micronutrientlimited fermentations likely originates from a posttranscriptional control mechanism, which is dependent on the limiting nutrient.

Actually, the TOR pathway that senses the nitrogen status of the cell controls the stress response in yeast. Because nitrogen is available in the medium in micronutrient-limited fermentations, nitrogen activates the TOR pathway in these starved conditions. This signalling pathway activation prevents the set up of the stress response as indicated by the fact that adding Rapamycin, a drug that blocks the TOR pathway, restored a high yeast viability in micronutrient-limited fermentations (data not shown, plos).

\subsection{Nitrogen sources have different capacity to trigger cell death}

We have examined the ability of a large set of nitrogen sources to trigger cell death in micronutrientlimited fermentations. We used the fermentation medium containing a low level $(71 \mathrm{mg} / \mathrm{L})$ of assimilable nitrogen provided by a combination of amino acids and ammonium. This medium was used in condition of oleic acid limitation. 


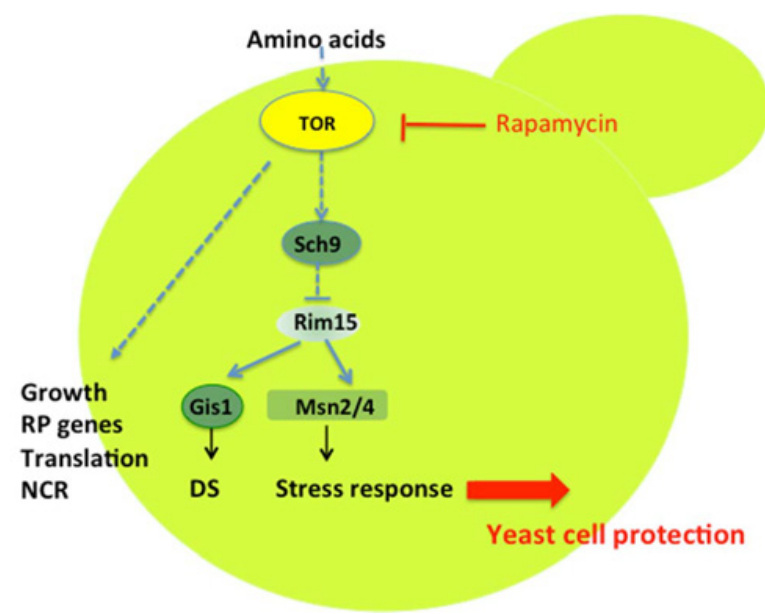

Figure 3. Sensing nitrogen through the TOR pathway and stress response.

Table 1. Classification of nitrogen sources according to their ability to trigger cell death in an oleic acid-limited fermentation. The nitrogen sources were added at a level of $354 \mathrm{mg} / \mathrm{L}$ Nass to a basal medium $74 \mathrm{mg} / \mathrm{L}$ Nass.

\begin{tabular}{|l|l|l|}
\hline $\begin{array}{l}\text { Low } \\
\text { ability }\end{array}$ & $\begin{array}{l}\text { Average } \\
\text { ability }\end{array}$ & $\begin{array}{l}\text { High } \\
\text { ability }\end{array}$ \\
\hline Alanine & Cystéine & Lysine \\
Arginine & Histidine & Phénylalanine \\
Asparagine & Proline & Tryptophane \\
Acide aspartique & Tyrosine & \\
Glutamine & Ammonium & \\
Acide glutamique & & \\
Glycine & & \\
Isoleucine & & \\
Leucine & & \\
Méthionine & & \\
Sérine & & \\
Thréonine & & \\
Valine & & \\
\hline
\end{tabular}

To assess the impact of individual nitrogen sources, each of 19 amino acids or $\mathrm{NH}_{4}^{+}$were added to this medium in amounts corresponding to $354 \mathrm{mg} / \mathrm{L}$ assimilable nitrogen, for a total of $425 \mathrm{mgL}$ Nass.

The nitrogen sources revealed different ability to trigger cell death in these micronutrients limited fermentations. The nitrogen sources were classified according to the cell death intensity capacity. A large group has only a weak ability to trigger cell death and contains the main amino acids available in a grape must in stationary phase (arginine). The two other group that have an average or high ability to induce cell death. The high capacity group likely reflect a toxicity of these amino acids at high level in such conditions which bases are unknown.

The group of intermediate ability to trigger cell death may be of high relevance in alcoholic fermentation because several sources can be found at high level. As shown Fig. 4, cysteine, histidine, proline and ammonium supplementation led to a loss of viability associated to stuck fermentations with residual sugars varying from $13 \mathrm{~g} / \mathrm{L}$ to $40 \mathrm{~g} / \mathrm{L}$. The control kinetic (without nitrogen addition) is slow but ferments all the sugars (squares).

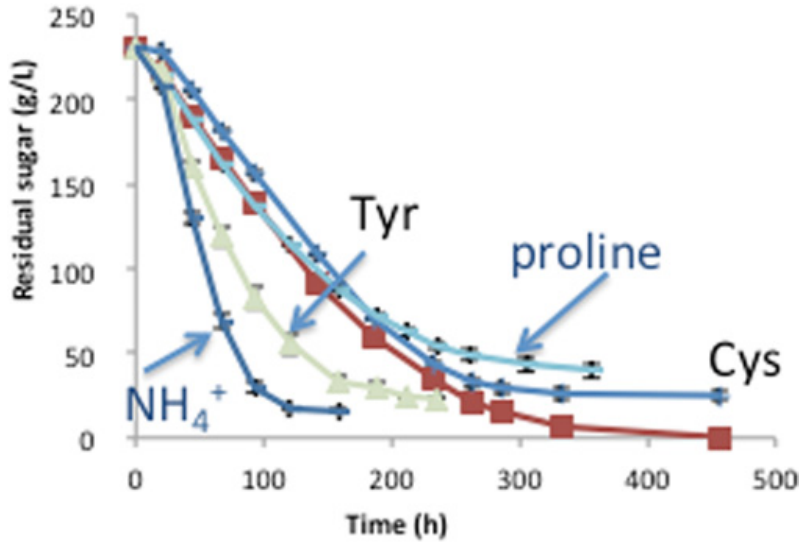

Figure 4. Impact of nitrogen source on fermentation kinetics. The control fermentation (squares) contained $71 \mathrm{mg} / \mathrm{L}$ Nass to which individual nitrogen source were added at $354 \mathrm{mg} / \mathrm{L}$ Nass.

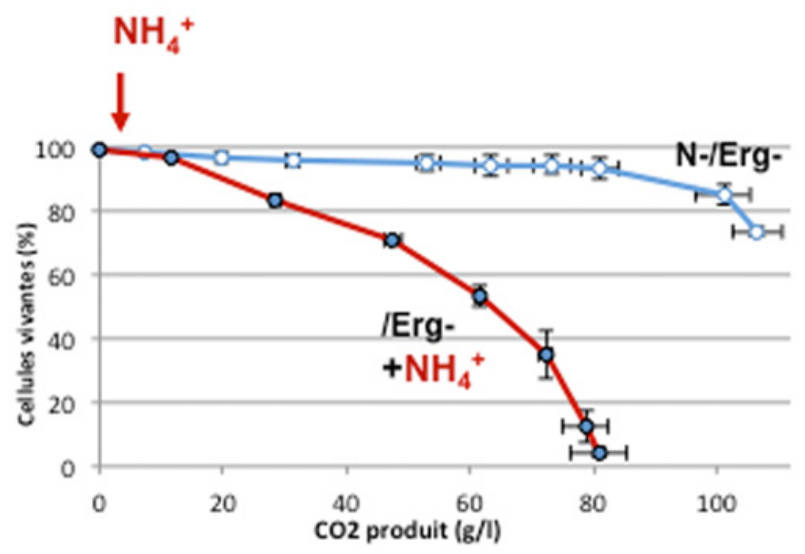

Figure 5. Impact of $\mathrm{NH}_{4}^{+}$addition ( $354 \mathrm{mg} / \mathrm{L}$ Nass) to an ergosterol-limited must.

Unexpectedly proline belongs to the group of sources that can trigger cell death while this amino acid is not metabolized during alcoholic fermentation. Its impact may be of relevance given that this amino acids remains in the must during all the fermentations.

Since we detected that $\mathrm{NH}_{4}^{+}$could trigger cell death, we examined whether this phenomenon was triggered in different micronutrient limited situations. We monitored cells death and kinetics in conditions of ergosterol-, pantothenic acid- and nicotinic acid-limited fermentations. As shown Fig. 5 for ergosterol limitation, the addition of $\mathrm{NH}_{4}^{+}$to the must (before the fermentation) triggered a strong cell death. A similar response was observed for pantothenic acid and nicotinic acid limitations. Therefore $\mathrm{NH}_{4}^{+}$has clearly a strong capacity to trigger cell death in various micronutrient deficient situation in nitrogen dependent way.

\section{Conclusion}

Understanding the mechanisms underlying yeast cell death is important to improve fermentation management and avoid stuck or sluggish fermentations. We show that cell death can be triggered by a set of micronutrient limitation when associated to high nitrogen levels. The mechanisms identified in this work can likely explain the occurrence of 
cell death in many wine making conditions. Clarification of grape musts is for example known to deplete the medium from lipids and probably represent a classical situation of micronutrient limitation (sterols, oleic acid related) that yeast have to face rather frequently. The occurrence of other micronutrient limitation is less documented but has to be considered in link with spontaneous microorganisms development in must in the early phases of the process. Similarly, the impact of novel practices such as sequential inoculation of yeasts may impact on the availability of micronutrients in musts.

Our data show that nitrogen plays a key role in the conditions that lead to cell death. Increasing the nitrogen level in grape must has to take into consideration this potential impact. Several nitrogen sources display a ability to trigger cell death and among them $\mathrm{NH}_{4}^{+}$. In some specific situation we could show that adding high amounts of $\mathrm{NH}_{4}^{+}$could have a detrimental impact on the fermentation kinetic. This capacity of has to be taken into consideration for must supplementation. We have shown that several amino acid did not display such cell death inducing capacity suggesting that organic nitrogen may be therefore more suitable in some circumstances than $\mathrm{NH}_{4}^{+}$. Our results highlight instead the necessity to take into account the micronutrients status to manage nitrogen supplementation during wine fermentation so as to avoid stuck fermentations.

\section{References}

[1] L.F. Bisson, Am. J. Enol. Vitic. 50, 1 (1999)

[2] H. Alexandre, V.L.T. Nguyen, M. Feuillat, C. Charpentier, Rev française d'oenologie 34, 146 (1994)

[3] V.M. Boer, S. Amini, D. Botstein 105, 19 (2008)

[4] C. Tesnière, P. Delobel, M. Pradal, B. Blondin, PLoS One 8, 4 (2013)

[5] C. Duc, M. Pradal, I. Sanchez, C. Tesniere, B. Blondin, PLoS One 12 (2017) 